\title{
Efecto redistributivo de la Política fiscal en El Salvador para el año 2012
}

\author{
Brenda Sofía Burgos \\ Catalina Galdámez \\ Paola Alejandra Peña \\ Gabriela Alejandra Ramírez \\ Universidad Centroamericana "José Simeón Cañas"
}

Resumen: En el presente trabajo se estudian los efectos de la estructura fiscal existentes en el 2012 para el caso de El Salvador, enfocándose en la capacidad redistributiva de dicha política sobre el ingreso de los hogares, representados por deciles de ingreso. Por tanto, se realiza un análisis exhaustivo sobre el impacto de los tributos y del gasto público social sobre la redistribución del ingreso y la desigualdad; todo a partir de micro datos obtenidos de la Encuesta de Hogares de Propósitos Múltiples, obteniendo resultados significativos que pueden usarse para la elaboración de futuras políticas fiscales.

Abstract: This paper presents the effects of fiscal structure existing in 2012 in the case of El Salvador, focusing on the redistributive capacity of the policy on household income, classified by income deciles. Therefore, a comprehensive analysis of the impact of taxes and social spending on income redistribution and inequality is made; everything from micro data from the Household Survey Multi-Purpose, obtaining significant results that can be used for the development of future fiscal policies.

Palabras clave

Economía, El Salvador, política fiscal, ingreso, desigualdad, gasto público social

\section{Keywords}

Economics, El Salvador, Fiscal Policy, Income, Unequality, Social Public Expenditure

\section{Introducción}

El presente trabajo de investigación abordará el estudio de la Política fiscal, implementada en El Salvador para el año 2012, para ello se analizarán los deciles poblacionales que son beneficiados o perjudicados a través de la redistribución real del ingreso que ha tenido la Política fiscal del año en mención. 
Por tanto, el objetivo general será realizar un análisis profundo del efecto redistributivo de la Política fiscal para ese año y sus principales contribuciones al mejoramiento del bienestar de la población. Para esto se hará uso de los datos presentados en la Encuesta de Hogares de Propósitos Múltiples

ingreso de los hogares para el año 2012, logrando disminuir la brecha de la desigualdad y polarización a través de una redistribución más equitativa de los ingresos entre los distintos deciles poblacionales.

Para ello, la investigación se ha estructurado en cuatro partes. Las primeras dos constan de un marco teórico y un análisis descriptivo del panorama económico y fiscal desde el año 2000 hasta el 2012. El análisis empírico se expondrá en
2012, base de datos del Banco Central de Reserva e Informe de Gestión Financiera del Estado de ese mismo año.

La hipótesis en torno a la cual gira dicha investigación es: La Política fiscal ha tenido un efecto positivo en la redistribución del

la tercera y cuarta parte, específicamente en la tercera parte se hará uso de métodos estadísticos que permiten presentar la distribución de los ingresos de los hogares, los tributos y el gasto público social realizado por el sector público por deciles de hogar del año 2012; para posteriormente, mostrar la evaluación del impacto y efectividad que ha tenido la Política fiscal de dicho año y las conclusiones que se desprenden de la investigación.

\section{Marco teórico}

El presente apartado se desarroIlará a partir de postulados teóricos sobre Política fiscal, recopilando posturas sobre diversos autores que desarrollan el tema fiscal y redistribución del ingreso.

\subsection{Política fiscal. Generalidades}

La Política fiscal es el instrumento a través del cual el gobierno participa en la actividad económica de un país, por medio de sus componentes básicos: los ingresos fiscales y el gasto público, así como a través de una acertada gestión de la deuda pública. Estas acciones, tienen como función principal elevar el nivel de bienestar general de la sociedad. (Capo, 2002.)

La función de redistribución que se deriva de la Política fiscal, se ve desde dos caras: el efecto de los tributos y el de los gastos públicos, en el cual un sistema tributario satisface el valor "equidad" cuando los sectores de mayor capacidad contributiva pagan una cuota de impuesto más elevada, respecto a los 
demás sectores. Los gastos públicos sociales en general cumplen con el criterio - aunque en una medida muy diversa, que debe cuantificarse- beneficiando más a los sectores desprotegidos o de menores recursos. (Santiere, 2002).

Para que la Política fiscal pueda lograr objetivos determinados, se vale de los siguientes instrumentos según Urquidi (1973): I. La política tributaria. II. La política de gasto público. III. La política de incentivos o gasto tributario. IV. La política de endeudamiento. V. La política financiera: Financiamiento Público y finanzas públicas, y Monetario.

\subsubsection{Elementos de Política fiscal}

Tomando en consideración que el mercado por sí solo no puede ejecutar todas las funciones económicas, se hace necesaria la política pública para guiarlo, corregirlo y complementarlo en determinados aspectos.

\section{a. Tributos}

Desde el punto de vista histórico, tributo es un término que proviene del latín tributum y que hace referencia a aquello que se tributa, lo cual significa ofrecer veneración como prueba de admiración o entregar al sector público cierta cantidad de dinero para las cargas públicas. Según Capo (2002), dicha herramienta puede clasificarse en:

\section{Recuadro 1 \\ Criterios que deben tener los tributos}

- Garantizar la máxima neutralidad económica.

- Costos mínimos de recaudación y pagos de tributos.

- Colocar tributos con la finalidad de hacerse de ingresos públicos.

- Definición clara de la base fiscal.

- No cobrar tributos sobre tributos.

- Equidad.

Tomado de Reconversión de la Política fiscal en El Salvador, por F. Lazo, 1996.

Tributos directos:

Gravamen que una administración estatal, regional o local establece sobre la renta, la propiedad o la riqueza de las personas o empresas. Un tributo directo es soportado en su totalidad por quien lo paga, y no puede ser transferido a otra entidad. Es decir, se conoce el contribuyente, y este paga de acuerdo a una característica.

\section{Tributos Indirectos:}

En este tributo no se conoce al contribuyente, es un tributo impersonal. El cobro se hace por alguna característica que tenga una acción económica, ya sea el consumo o venta de factores. Estos son recaudados por el sector público, una región o un ente local sobre el consumo, el gasto o un derecho, pero no sobre los ingresos o la propiedad. 


\section{Recuadro 2 Manejo del gasto público social}

- $\quad$ Programación de las acciones o proyectos

- Equilibrio con los ingresos

- Racionalizar los gastos según importancia

- Transparencia y difusión

- $\quad$ Flexibilidad ante cambios vertiginosos

Tomado de El impacto redistributivo de la Política fiscal en El Salvador en 1998, por R. Díaz \& M., Merlos, 2000.

\section{b. Gasto público}

El gasto público es la cantidad de recursos financieros, materiales y humanos que el sector público -representado por el gobiernoemplea para el cumplimiento de sus funciones, entre las que se encuentran, de manera primordial, la de satisfacer los servicios públicos de la sociedad. Asimismo, por medio de este, el gobierno influye en los niveles de consumo, inversión, empleo, etc. Por tanto, es considerado como una devolución de recursos económicos que se hace a la sociedad, proveniente de lo captado por el gobierno vía ingresos públicos, principalmente por medio de su sistema tributario (Ibarra Mares, 2010).

Con base en su clasificación económica, el gasto programable del sector público se divide según la SHCP (Secretaria de Hacienda y Crédito Público de México, 2010), en:
Gasto Corriente

Se refiere a la adquisición de bienes y servicios que realiza el sector público durante el ejercicio fiscal, sin incrementar el patrimonio público. Este tipo de gasto incluye las erogaciones necesarias para el funcionamiento de las instituciones del gobierno; así también, las remuneraciones hacia los empleados públicos.

\section{Gasto de Capital}

Se refiere a las erogaciones que incrementan el patrimonio público e incluye el gasto de inversión que realizan las dependencias y entidades de la administración pública.

\subsubsection{Redistribución Equitativa}

Según Capo (2002), la función redistributiva refleja la preocupación por la equidad y la cohesión dentro de un grupo. Esta tiene como objetivo compensar las desigualdades estructurales entre regiones, medidas por la renta per cápita de sus habitantes. El concepto de equidad dentro de las políticas de gobierno se determina a través de dos principios rectores, los cuales según Santiere (2002) son:

\section{El Beneficio}

Presenta los tributos como el precio que los individuos deben pagar por el uso de los bienes públicos. 
La Capacidad de pago

Solo considera el aspecto de los tributos y está relacionado con los conceptos de equidad, tanto horizontal como vertical. La equidad horizontal significa que similares unidades pagadoras de tributos deben abonar similares cantidades del gravamen. La equidad vertical determina que exista un tratamiento distinto para distintos contribuyentes, es decir, pagan según sus ingresos.

Según estos dos principios, dentro de la Política fiscal la redistribución equitativa se ve influenciada positivamente a través de:

a. Un sistema de tributos progresivo: fija la imposición progresiva de renta sobre aquellas familias que poseen una mayor capacidad contributiva. Un tributo que se determine como regresivo impactará de forma negativa sobre los estratos de ingresos inferiores.

b. Un sistema de gastos progresivo: dispone la subvención del sector público a través del gasto público sobre aquellas familias de ingresos más bajos que el resto.

\subsection{Herramientas para el Análisis de Distribución y Redistribución del Ingreso}

Una de las funciones fundamentales que tiene la Política fiscal, es su papel redistribuidor de los ingresos, la efectividad de la Política fiscal dependerá de qué tan significativo es el cambio en la nueva distribución de ingresos y si contribuye en la reducción de la pobreza y desigualdad.

\subsubsection{Herramientas para el Análisis de los Ingresos}

Las principales herramientas que se tomarán en esta investigación para determinar el estado de los ingresos de la población son los siguientes:

\section{a. Curva de Lorenz}

Probablemente una de las maneras más habituales de presentar la desigualdad es a partir de la Curva de Lorenz, la cual representa el porcentaje acumulado de ingreso () recibido por un determinado grupo de población (), ordenado de forma ascendente - en percentiles, cuartiles, quintiles o deciles - de acuerdo a la cuantía de su ingreso (, esto según Medina (2001. 


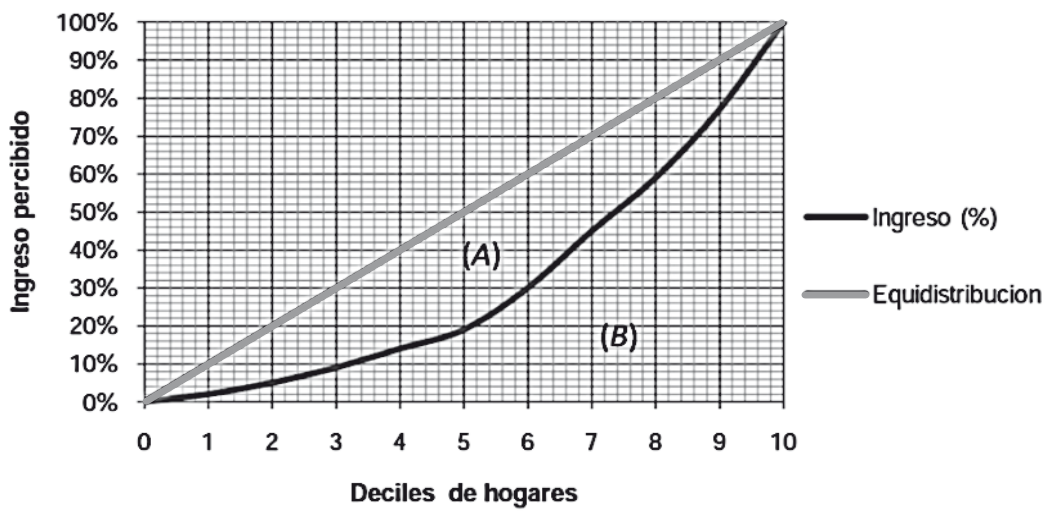

Tomado de Incidencia de la Política fiscal en la redistribución del ingreso en El Salvador en el 2008, por J. Álvarez, J. Arias, \& O. Moreno, 2010.

Como puede observarse en la Ilustración 1, en el eje horizontal se establece el ordenamiento de la población $\left(\mathrm{P}_{\mathrm{i}}\right)$ y en el eje vertical el porcentaje de ingresos $\left(\% Y_{i}\right)$, de igual forma se desprende:

- La línea de equidistribución: divide en dos partes el gráfico y consta de la línea de $45^{\circ}$; se forma cuando a cada porcentaje de la población le corresponde el mismo porcentaje de ingresos, es decir, denota ausencia de desigualdad.

- La Curva de Lorenz: siempre se ubica por debajo de la diagonal, en la medida que los ingresos de los individuos se encuentran ordenados en forma creciente y viceversa. En la medida que la Curva de Lorenz se aproxime a la diagonal, sería una situación de mayor igualdad, mientras que cuando se aleja, la desigualdad incrementa.

- Área de concentración: área entre la línea de equidad perfecta y la Curva de Lorenz; a partir de esta se derivan indicadores que miden la concentración del ingreso (área A).

\section{b. Índice de Gini}

Uno de los índices más usados en el estudio de la desigualdad es el Coeficiente de Concentración de Gini, ideado por el estadístico Corrado Gini en 1912, este pondera cuantitativamente el grado de desigualdad en la estructura de ingreso de un país.

El valor del coeficiente fluctúa entre 0 y 1 ; cuando se aproxima a cero, refleja una distribución del ingreso más o menos igualitaria, cuando el valor del coeficiente 
se aproxima a uno, muestra una distribución regresiva concentrada en pocas personas, acercándose así a una situación de desigualdad absoluta.

En este sentido, y según Medina (2001), la línea de equidistribución sirve para comparar la manera en que están distribuidos los ingresos; mientras más se aleja la curva de la diagonal (valor cero), mayor será la concentración del ingreso y viceversa. Si el coeficiente es cero, no existe concentración y si el coeficiente es igual a uno, significa que el ingreso está concentrado en una sola persona

\section{c. Índice de Duclos, Esteban y Ray}

El indicador construido por Esteban y Ray pretende modelizar la polarización a partir de dos hechos principales: homogeneidad dentro de los grupos y heterogeneidad entre los grupos, pues se asume que estos aumentan la polarización. Según Lasso de La Vega \& Urrutia (s.f) este índice se basa en los siguientes axiomas:

- Cuanta mayor homogeneidad exista dentro de los grupos mayor es el grado de polarización.

- Cuanta mayor heterogeneidad exista entre los grupos mayor es el grado de polarización.

- La polarización afecta a los grupos. Cuanto menor sea el número de grupos de tamaño significativo mayor es la polarización. Además, los individuos aislados tienen muy poco peso en la misma.

El índice de polarización Duclos, Esteban y Ray (DER) para el caso de distribuciones continuas está dado por:

$$
P_{D E R}: \iint f(x)^{1+\alpha} f(y)|y-x| \mathrm{d} y \mathrm{~d} x \text { Donde } \alpha \in[0.25,1]
$$

En la expresión $y$ y $x$ anterior, y son, respectivamente, la renta $y$ el tamaño del grupo. El parámetro $\alpha$ indica el grado de aversión a la polarización. El índice de polarización de DER tiene resultados entre 0 y 1 , entre más se acerca a 1 se dice que hay un mayor nivel de polarización.

\subsubsection{Herramientas para el Análisis de los Tributos y Gasto Público Social}

Según Martín \& Olmedo (1999) la aplicación de los desarrollos teóricos en materia de progresividad y efecto redistributivo del gasto público social es similar al análisis de tributos, con ciertas 


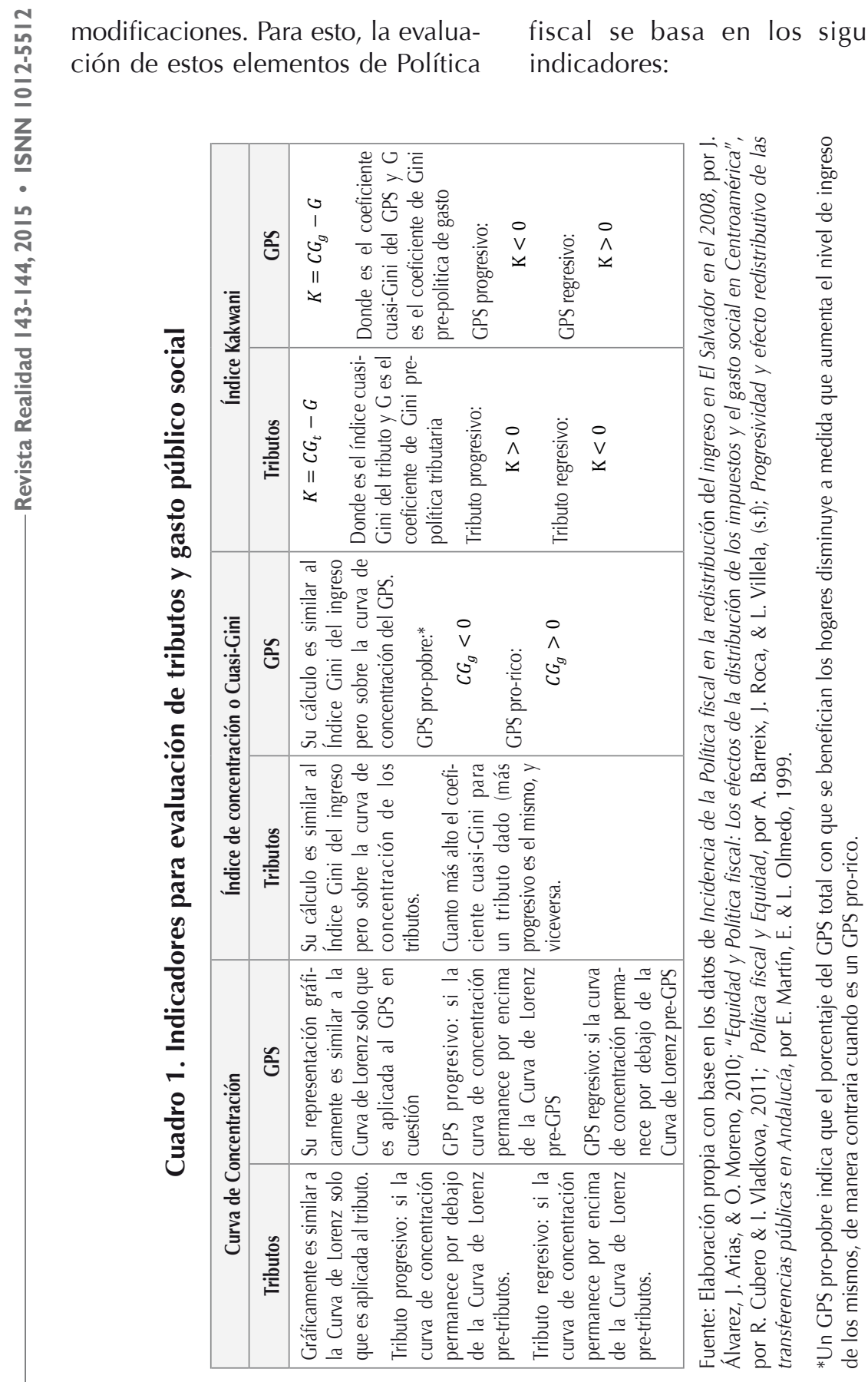


Estos indicadores darán la perspectiva del efecto que ha tenido la imposición de los tributos y los proyectos de gasto público social hacia los diferentes sectores de la población, de este modo se dará lugar a una evaluación sobre el desempeño, desde un enfoque estático.

\subsubsection{Efecto Redistributivo y Efecto Bienestar de la Política fiscal}

Para efectos de análisis de la Política fiscal y su incidencia en el bienestar social, se definirá este como una mejora en la distribución de ingresos, de modo que disminuya la desigualdad entre deciles, mostrando una situación de mayor equidad. Dado lo anterior, se determinará el mayor o menor nivel de bienestar con base en el grado de desigualdad.

Para confrontar los niveles de bienestar de dos situaciones diferentes es necesario hacer una comparación de las curvas de Lorenz. A continuación, se puede observar posibles comparaciones de bienestar:

\section{Ilustración 2: Diferentes curvas de Lorenz}

Las curvas de Lorenz no se cruzan

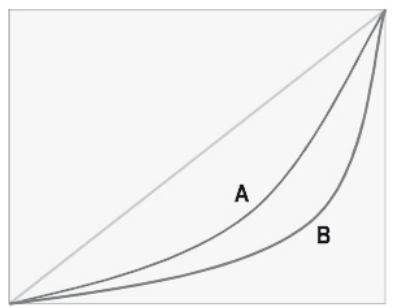

Si LA "domina" LB y $\mu \mathrm{A} \geq \mu \mathrm{B} \Rightarrow$ bienestar es mayor en $A$

Donde:

LB: Lorenz B

LA: Lorenz A

LG: Lorenz generalizada

LGA: Lorenz generalizada A

LGB: Lorenz generalizada B $\mu$ Media de la distribución.
Otras situaciones

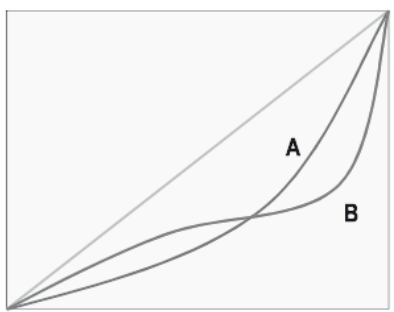

Si LA “domina" LB y $\mu B>\mu A \Rightarrow$ Se compara LG

Si LA y LB se cruzan pero LGA y LGB no $\Rightarrow$ Se compara LG

Si LGA y LGB se cruzan $\Rightarrow$ no es posible realizar comparaciones de bienestar.

Fuente: elaboración propia con base en los datos de Revisión de algunos indicadores para medir desigualdad, por X. Mancero. (s.f) 
Las curvas de Lorenz Generalizadas son útiles para valorar el bienestar, siempre y cuando se tome en cuenta el nivel de renta de los hogares, así como sus diferentes necesidades, esto según Gradín \& del Río (2001).

\section{Contexto Histórico: antecedentes y desarrollo de la Política fiscal en El Salvador}

En el primer apartado de esta segunda parte, se expone el panorama económico y social de $\mathrm{El}$ Salvador alrededor del año 2012. En un segundo momento, se muestran algunas de las medidas implementadas en materia de Política fiscal y de igual forma, se analiza el desempeño fiscal del Sector Público.

\subsection{Entorno Económico y Social de El Salvador}

El Salvador es un país con una Economía pequeña y dolarizada, con una población de 6.25 millones, para el año 2012, y que presenta un crecimiento del Producto Interno Bruto (PIB) del $1.9 \%$. La economía tiene una alta dependencia de la remesas, provenientes en su mayoría de Estados
Unidos, las cuales alcanzan US\$ 3,911 millones representando el $16.38 \%$ sobre el PIB, cifra superior a años anteriores de 2012 (Ver Cuadro 2).

En el ámbito social, la pobreza es un problema que afecta a casi el $40 \%$ de la población total del país. Según el Gráfico 1, el nivel de pobreza alcanzado para el año 2012 fue de $34.5 \%$ del total de la población salvadoreña, viviendo en condiciones de pobreza extrema el $8.9 \%$ de los habitantes, y en pobreza relativa el $25.6 \%$. En dicha situación, se observa una leve mejora en comparación de los años anteriores (2008 a 2011), a pesar de ello, ha sido insuficiente para mejorar significativamente dicho problema en el área rural.

Cuadro 2. Principales indicadores macroeconómicos. El Salvador 2010-2012

\begin{tabular}{|c|c|c|c|c|c|c|}
\hline Indicadores & & 2010 & & 2011 & & 2012 \\
\hline Población (millones de hab.) & & 6.18 & & 6.21 & & 6.25 \\
\hline Población económicamente activa (millones.) & & 2.58 & & 2.64 & & 2.72 \\
\hline PIB nominal (millones de US\$) & $\$$ & 21,428 & $\$$ & 23,054 & $\$$ & 23,865 \\
\hline Per cápita (US\$) & $\$$ & 3,467 & $\$$ & 3,710 & $\$$ & 3,819 \\
\hline Crecimiento real del PIB (\%) & & $1.4 \%$ & & $1.5 \%$ & & $1.9 \%$ \\
\hline Remesas (Millones de US\$) & $\$$ & 3,431 & $\$$ & 3,649 & $\$$ & 3,911 \\
\hline
\end{tabular}




\begin{tabular}{|l|rr|rr|rr|}
\hline \multicolumn{1}{|c|}{ Indicadores } & \multicolumn{2}{c|}{2010} & \multicolumn{2}{c|}{2011} & \multicolumn{2}{c|}{2012} \\
\hline Inversión Extranjera Directa & $\$$ & 117 & $\$$ & 385 & $\$$ & 516 \\
\hline Exportaciones (bienes + servicios) & $\$$ & 5,475 & $\$$ & 6,382 & $\$$ & 6,767 \\
\hline Bienes & $\$$ & 4,499 & $\$$ & 5,309 & $\$$ & 5,339 \\
\hline Servicios & $\$$ & 976 & $\$$ & 1,073 & $\$$ & 1,428 \\
\hline Importaciones (bienes + servicios) & $\$$ & 9,486 & $\$$ & 11,071 & $\$$ & 11,096 \\
\hline Bienes & $\$$ & 8,416 & $\$$ & 9,965 & $\$$ & 10,270 \\
\hline Servicios & $\$$ & 1,070 & $\$$ & 1,106 & $\$$ & 826 \\
\hline
\end{tabular}

Fuente: Elaboración propia con base en datos de BCR, 2010-2012.

En el ámbito comercial, el país es altamente dependiente de productos importados, alcanzando un valor de US\$11,096 millones, mientras el valor de las exportaciones es de US\$6,767 millones. Esta situación profundiza el déficit de la balanza comercial; de igual forma, la Inversión Extranjera Directa (IED) alcanzó los US\$516 millones en el año 2012, superior a años anteriores.
Aunado a esta situación, como lo sostiene Pleitéz (2001), está el problema de la desigualdad económica y social, que ocurre por irregularidades de mercado que limita el acceso de la población a empleos formales, y además, por los débiles esfuerzos por parte del gobierno para corregir las deficiencias.

\section{Gráfico 1. Hogares salvadoreños en condición de pobreza El Salvador 2000-2012 -Porcentaje-}

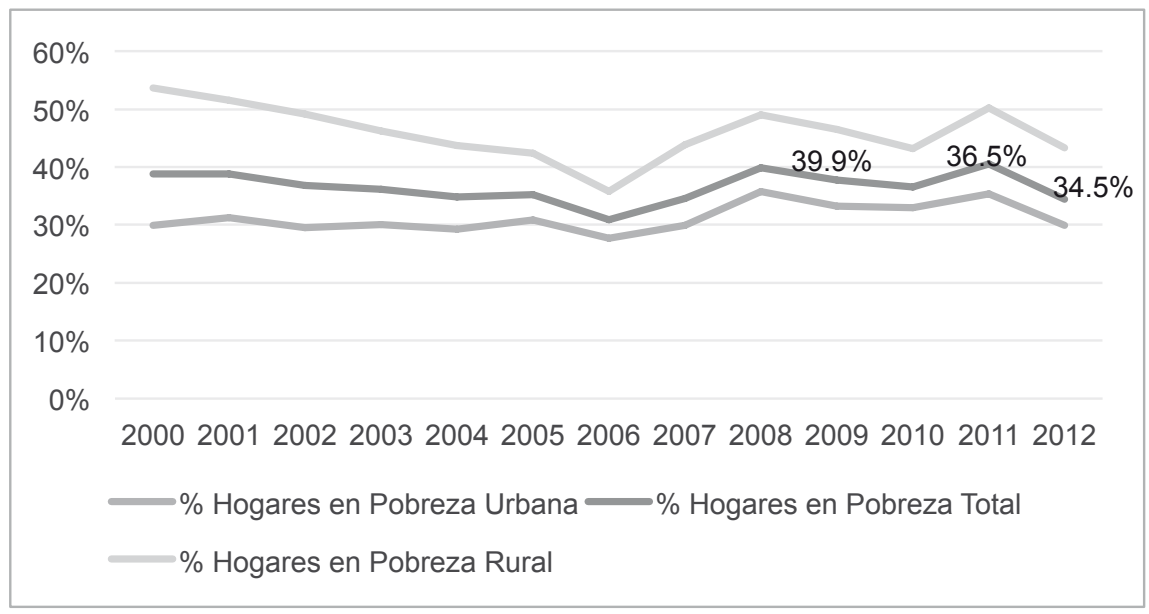

Fuente: Elaboración propia con base en datos de MINEC/DIGESTYC, varios años. 


\subsection{Principales Políticas fiscales Implementadas en el periodo 2009-2012}

Según el Informe de la gestión financiera del Estado del Ministerio de Hacienda (2012), el 2009 fue un año importante en la historia de El Salvador, por marcar el inicio del primer gobierno de izquierda que llega al poder vía elecciones. La Política fiscal para el período 2010-2014 planteó el objetivo de asegurar que el país contara con los recursos necesarios para financiar los gastos sociales y económicos prioritarios en el marco del Plan Quinquenal de Desarrollo, asegurando que los recursos se invirtieran de manera honesta, eficiente y transparente, garantizando la sostenibilidad fiscal.
Teniendo en cuenta esto, se llevaron a cabo dos reformas tributarias (2009 y 2011), enfocadas en aumentar los recursos económicos del Sector Público para financiar programas sociales que eran parte del Plan Quinquenal, y en reducir la regresividad característica del sistema tributario, obteniendo rendimientos de US\$297.5 millones, equivalentes al $1.3 \%$ del PIB, después de aplicadas las reformas, esto según los datos del GOES (2013).

Según el Ministerio de Hacienda (año de referencia a,b, c), los rendimientos obtenidos a partir de las primeras reformas, representaron un incremento total de US\$137.8 millones en los años 2010 y 2011 y las segundas reformas —efectuadas en el año 2011- incrementaron la recaudación a US\$159.7 millones.

\section{Cuadro 3. Reformas fiscales. El Salvador 2009 y 2011}

\begin{tabular}{|c|c|}
\hline Reforma 2009 & Reforma 2011 \\
\hline $\begin{array}{l}\text { Reformas a: } \\
\text { - } \quad \text { Ley de Impuestos sobre la Renta (ISR) } \\
\text { - } \quad \text { Ley de IVA } \\
\text { - } \quad \text { Código Tributario } \\
\text { - } \quad \text { Ley de impuestos sobre productos de tabaco } \\
\text { - Ley reguladora de la producción y comercialización } \\
\text { de alcohol y bebidas alcohólicas } \\
\text { - } \quad \text { Nuevas Leyes: } \\
\text { - Ley de Impuesto Especial a Combustibles } \\
\text { - Ley de Impuesto a Primera Matrícula } \\
\text { Gaseosas y Jugos a las Bebidas Carbonatadas, }\end{array}$ & $\begin{array}{l}\begin{array}{l}\text { Reformas a la Ley de Impuestos sobre la } \\
\text { Renta (ISR): }\end{array} \\
\text { - } \quad \text { Declaraciones } \\
\text { Incremento de } 25 \% \text { a } 30 \% \\
\text { Aplicación de tributo mínimo (1\%) Incremento pago } \\
\text { a cuenta Modificación a las personas naturales } \\
\text { - Retenciones } \\
\text { Distribución de dividendos } \\
\text { - Modificación de tablas de retención }\end{array}$ \\
\hline
\end{tabular}

Fuente: elaboración propia con base en datos del (nombre de la publicación), Ministerio de Hacienda. 


\subsection{Evolución de los ingresos y gastos públicos}

Para determinar la situación del sector público no financiero, ha sido útil el análisis que se basa en los ingresos netos y gastos sociales que se efectúan. La manera de proceder de parte de este sector, se verá reflejado en el déficit o superávit fiscal y cobrará importancia el manejo que se tenga con la deuda pública (ver Gráfico 2).

$\mathrm{Al}$ igual que en otros países de Centroamérica, en El Salvador los tributos recaudados representan alrededor del $75 \%$ de los recursos totales incluidos en el Presupuesto de Ingresos y Gastos del Sector Público; los ingresos no tributarios son la segunda fuente de ingresos públicos, que representan aproximadamente $16 \%$ (Medina, et al., 2013).

En el Gráfico 2 se muestra que el IVA es el tributo que mayor porcentaje aporta dentro de la estructura de ingresos tributarios, alcanzando en promedio el $51.4 \%$ del aporte total, seguido está el Impuesto Sobre la Renta (ISR), segundo tributo que más aporta a la estructura.

Asimismo, se ha dado un incremento relativo en la recaudación del ISR, único tributo directo en el sistema tributario; la mayor participación del mismo, dentro de la estructura tributaria, se da a partir de las reformas fiscales realizadas en los años 2009 y 2011. De un 31.9\% en el año 2000, pasó a representar un $36.4 \%$ en el año 2012, con una tasa anual de crecimiento promedio de $1.2 \%$.

A pesar de que existen teorías modernas para el cálculo del ISR (con las que se cobra sobre el total del ingreso percibido) en El Salvador se gravan por separado los distintos tipos de renta que percibe un mismo contribuyente; esto dificulta lograr una equidad en el sistema tributario, pues contribuyentes con ingresos similares deben contribuir con montos diferentes de tasa tributaria. Otra característica que obstaculiza la equidad es la utilización de tratamientos tributarios preferentes, al reducir la capacidad recaudatoria del tributo e introducir ventajas competitivas para ciertos sectores (Medina, et al., 2013).

En cuanto al comercio exterior, los Derechos Arancelarios a la Importación (DAI) presentan una tendencia decreciente a lo largo del periodo de estudio, pasando de un $10.5 \%$ en el año 2000 a un $5.2 \%$ en el año 2012. La baja en la recaudación de DAI se debe a la desgravación arancelaria vinculada con los tratados de libre comercio, suscritos con el resto del mundo.

Las contribuciones especiales son tributos aplicados a determinados productos específicos $y$ tienen como objetivo financiar 
determinadas áreas de la actividad económica. Entre dichas áreas se encuentra la Contribución para el Fondo Vial y para el transporte público, el cual recae sobre la comercialización doméstica e importada de diesel y gasolinas. También, existe el tributo que pagan los productores de caña, centrales azucareras o ingenios por cada libra de azúcar extraída y la contribución para la promoción turística.

Además, se tiene el tributo indirecto a productos especiales, aplicado - selectivamente- al consumo de bebidas alcohólicas, energizantes, gaseosas y bebidas no alcohólicas como jugos de frutas, asimismo al combustible, a los cigarrillos y al tabaco. No representan un porcentaje grande de la recaudación tributaria, a pesar que con las reformas se aplica el tributo tanto a cantidad consumida como valor del bien; es decir, se ha aplicado un tributo ad-valorem, además del tributo específico que ya se tenía.
- Según Cubero y Vladkova (2011), el sistema tributario salvadoreño, a pesar de las distintas Reformas fiscales, sigue presentando las siguientes tendencias:

- Fortalecimiento de los ingresos tributarios, pero con un volumen insuficiente para financiar las demandas crecientes del Sector Público.

- Creciente importancia de los tributos generales al consumo y al valor agregado.

- Tributos específicos o selectivos al consumo, con bajo rendimiento y gran dispersión en sus tasas.

- Importancia decreciente de los tributos al comercio exterior.

- Amplio uso de exoneraciones fiscales.

- Leve aumento de los tributos directos con debilidades. 


\section{Gráfico 2. Desempeño fiscal del Sector Público no Financiero. \\ El Salvador 2000-2013}
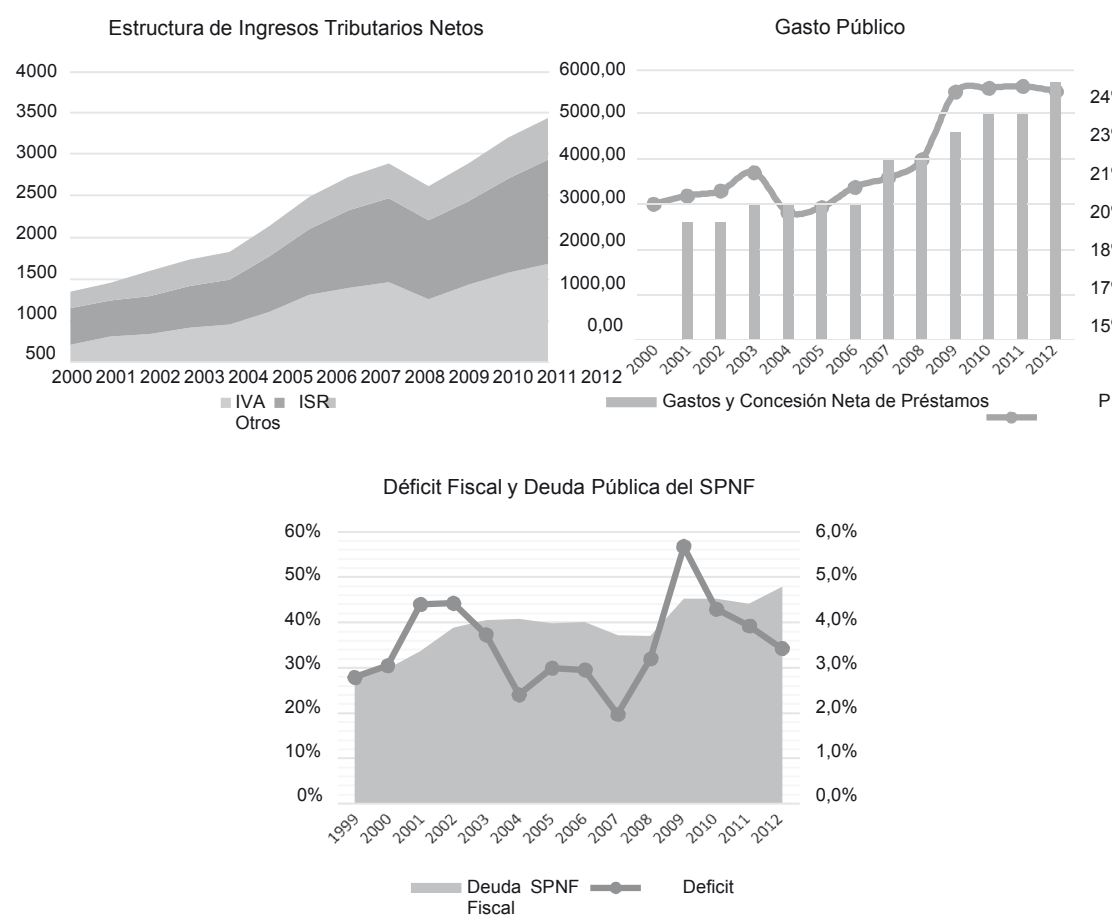

Fuente: Elaboración propia con base en datos de BCR, varios años.

Todas las características mencionadas hacen el sistema tributario salvadoreño inequitativo y con dificultades para financiar la administración pública, en especial durante etapas de recesión y crisis.

El impacto total del gasto social, sobre la distribución del ingreso, depende de la magnitud del mismo y su asignación según los distintos estratos de ingresos. El gasto social incluye gasto de capital y corriente en educación, salud, protección social (seguro de salud y asistencia social), vivienda, agua, cloacas, cultura, deportes y recreación (Cubero \& Vladkova, 2011).

En El Salvador, al igual que otros países de la región, el gasto público tiene como característica principal su alta rigidez. El $85 \%$ de los recursos están pre asignados por ley, impidiendo un margen de maniobra por parte de las autoridades para ejecutar algunos programas sociales o económicos de interés social. Asimismo, se añaden problemas de baja 
ejecución, ineficiencia, baja calidad y otros provenientes de una mala planificación, impidiendo obtener resultados tangibles (Medina, et al., 2013).

\section{Distribución de la Política fiscal por deciles de hogares en el año 2012}

En el presente apartado se realizarán algunas estimaciones claves _las cuales se basan en la segmentación de los hogares en diez niveles de ingresos o deciles de ingreso- para obtener la distribución de los ingresos de los hogares, de tributos directos e indirectos y del gasto realizado por el sector público, con el propósito de estimar el impacto de la Política fiscal en el año 2012.

\subsection{Distribución del ingreso, gasto y ahorro por deciles de Hogares}

Cada año, la Dirección de Estadísticas y Censos (DIGESTYC) realiza la Encuesta de Hogares de Propósitos Múltiples (EHPM) para estimar ingresos y gastos de los hogares salvadoreños, al mismo tiempo brinda los insumos necesarios para realizar un diagnóstico de la situación del país. Para el año 2012 se obtiene una muestra representativa de 19, 968 hogares, a partir de la cual se infieren resultados a nivel nacional.
Debido a que la EHPM presenta sesgos estadísticos por el lado del gasto, la metodología utilizada ha sido crear una estructura de ingresos, tributos y gasto público social, a la cual se le puedan asociar cifras reales de cuentas nacionales o de información oficial publicadas por el Banco Central de Reserva, Ministerio de Hacienda, entre otros. Esto conlleva a que las probabilidades de errores por omisión de información sean menores.

\subsubsection{Ingresos de Hogares}

A través de la EHPM 2012, se ha calculado una distribución porcentual del ingreso por deciles de hogares, evaluando los rangos a nivel total del país, tomando como variable el ingreso familiar reportado por dicha encuesta. A esta estructura porcentual, se aplica al "Ingreso Nacional Bruto Disponible" privado en el año 2012, reportado por el Banco Central de Reserva de El Salvador (BCR), y cuyo monto asciende a $\$ 24,024.3$ millones; obteniendo así una estimación real del ingreso familiar por deciles de hogar. 
Tabla 1. Distribución del ingreso real por deciles de hogares para el año 2012 -Porcentaje/Dólares-

\begin{tabular}{|c|c|c|c|c|c|c|c|}
\hline \multirow{2}{*}{ Deciles } & \multirow{2}{*}{$\begin{array}{l}\text { Estructura } \\
\text { Porcentual }\end{array}$} & \multirow{2}{*}{\multicolumn{2}{|c|}{ Ingreso Real Anual }} & \multicolumn{4}{|c|}{ Ingreso promedio/hogar } \\
\hline & & & & & ensual & & Anual \\
\hline Primero & $1.77 \%$ & $\$$ & $425,521,779.98$ & $\$$ & 217.91 & $\$$ & $2,614.91$ \\
\hline Segundo & $3.13 \%$ & $\$$ & $751,616,414.80$ & $\$$ & 384.54 & $\$$ & $4,614.51$ \\
\hline Tercero & $4.28 \%$ & $\$$ & $1,028,072,161.09$ & $\$$ & 526.20 & $\$$ & $6,314.36$ \\
\hline Cuarto & $5.37 \%$ & $\$$ & $1,289,029,640.90$ & $\$$ & 660.28 & $\$$ & $7,923.37$ \\
\hline Quinto & $6.62 \%$ & $\$$ & $1,589,440,836.77$ & $\$$ & 812.92 & $\$$ & $9,755.06$ \\
\hline Sexto & $8.18 \%$ & $\$$ & $1,965,423,356.40$ & $\$$ & $1,006.56$ & $\$$ & $12,078.71$ \\
\hline Séptimo & $9.90 \%$ & $\$$ & $2,378,364,933.20$ & $\$$ & $1,217.33$ & $\$$ & $14,607.95$ \\
\hline Octavo & $12.35 \%$ & $\$$ & $2,966,523,271.83$ & $\$$ & $1,517.30$ & $\$$ & $18,207.57$ \\
\hline Noveno & $16.35 \%$ & $\$$ & $3,927,024,067.46$ & $\$$ & $2,009.33$ & $\$$ & $24,111.99$ \\
\hline Décimo & $32.07 \%$ & $\$$ & $7,703,283,537.57$ & $\$$ & $3,944.72$ & $\$$ & $47,336.66$ \\
\hline Total & $100.00 \%$ & $\$$ & $24,024,300,000.00$ & $\$$ & $1,229.67$ & $\$$ & $14,755.98$ \\
\hline
\end{tabular}

Fuente: Elaboración propia con base en datos del BCR (2012) y EHPM (2012).

Los resultados de la Tabla 1 muestran una alta concentración de ingresos en los hogares de deciles más altos, mientras que los deciles más bajos se apropian de un porcentaje muy reducido de los ingresos totales. El $40 \%$ de los hogares con menores ingresos, apenas concentran el $14.55 \%$ de los ingresos, a diferencia del $10 \%$ de los hogares con mayores

\subsubsection{Gastos de Hogares}

A continuación se presenta la estructura porcentual del gasto real ajustado, la cual ha sido aplicada al "Consumo privado" presentado por el BCR para el año 2012 - cuyo monto asciende a $\$ 22,111.1$ millones-, presentado en la Tabla 2.

A partir de la Tabla 2 se observa que el decil décimo realiza un gasto real en consumo anual de aproximadamente US\$6,295, 939, 555 lo que representa 14.8 veces el consumo del primer decil. El gasto real por rubro, para cada decil de hogar, se detalla en el Tabla 3, a partir del cual se ajustará cada partida de datos que se utilizarán en los siguientes apartados, y así para obtener gastos reales específicos. 
Tabla 2. Distribución del gasto real por deciles de hogares para el año 2012 -Porcentajes/Dólares-

\begin{tabular}{|l|c|rr|}
\hline \multicolumn{1}{|c|}{ Deciles } & Estructura & \multicolumn{2}{|c|}{ Gasto Familiar Real } \\
\hline Primero & 1.92 & $\$$ & $425,521,779.98$ \\
\hline Segundo & 3.40 & $\$$ & $751,616,414.80$ \\
\hline Tercero & 4.65 & $\$$ & $1,028,072,161.09$ \\
\hline Cuarto & 5,83 & $\$$ & $1,289,029,640.90$ \\
\hline Quinto & 7.19 & $\$$ & $1,589,440,836.77$ \\
\hline Sexto & 8.89 & $\$$ & $1,965,423,356.40$ \\
\hline Séptimo & 10.67 & $\$$ & $2,359,990,584.33$ \\
\hline Octavo & 12.58 & $\$$ & $2,780,532,961.99$ \\
\hline Noveno & 16.40 & $\$$ & $3,625,532,708.11$ \\
\hline Décimo & 28.47 & $\$$ & $6,295,939,555.62$ \\
\hline Total & $\mathbf{1 0 0 . 0 0} \%$ & $\mathbf{\$}$ & $\mathbf{2 2 , 1 1 1 , 1 0 0 , 0 0 0 . 0 0}$ \\
\hline
\end{tabular}

Fuente: Elaboración propia con base en datos de BCR (2012) y EHPM (2012).

Tabla 3. Distribución del gasto real por deciles de hogares, según rubro de gasto para el año 2012 -Miles de dólares-

\begin{tabular}{|c|c|c|c|c|c|c|c|c|}
\hline Deciles & $\begin{array}{c}\text { Gasto en } \\
\text { Alimentos }\end{array}$ & $\begin{array}{c}\text { Gasto en } \\
\text { artículos y } \\
\text { servicios }\end{array}$ & $\begin{array}{c}\text { Gasto en } \\
\text { Educación }\end{array}$ & $\begin{array}{l}\text { Gasto en } \\
\text { Vivienda }\end{array}$ & $\begin{array}{l}\text { Gasto en } \\
\text { Salud }\end{array}$ & Misceláneos & $\begin{array}{l}\text { Gasto Total } \\
\text { del Hogar }\end{array}$ & $\begin{array}{l}\text { Estructura } \\
\text { porcentual }\end{array}$ \\
\hline Primero & $\$ 265,703$ & $\$ \quad 53,083$ & $\$ \quad 33,442$ & $\$ \quad 49,872$ & $\$ \quad 3,664$ & $\$ \quad 19,758$ & $\$ \quad 425,522$ & $1.92 \%$ \\
\hline Segundo & $\$ 435,100$ & $\$ \quad 87,165$ & $\$ \quad 76,709$ & $\$ \quad 95,396$ & $\$ \quad 9,393$ & $\$ \quad 47,854$ & $\$ 751,616$ & $.40 \%$ \\
\hline Tercero & $\$ 524,918$ & $\$ 111,574$ & $\$ 111,307$ & $\$ 152,336$ & $\$ 17,315$ & $\$ \quad 110,622$ & $\$ 1,028,072$ & $65 \%$ \\
\hline Cuarto & $\$ 631,169$ & $\$ 136,568$ & $\$ 154,438$ & $\$ 203,906$ & $\$ 13,150$ & $\$ \quad 149,798$ & $\$ 1,289,030$ & $3 \%$ \\
\hline Quinto & $\$ 759,012$ & $\$ 164,556$ & $\$ 195,564$ & $\$ 241,901$ & $\$ 22,322$ & $\$ \quad 206,086$ & $\$ 1,589,441$ & $19 \%$ \\
\hline Sexto & $\$ 852,564$ & $\$ 192,886$ & $\$ 272,006$ & $\$ 340,035$ & $\$ 22,599$ & $\$ 285,333$ & $\$ 1,9$ & $89 \%$ \\
\hline Séptimo & $\$ 943,908$ & $\$ 229,264$ & $\$ 325,747$ & $\$ 445,087$ & $\$ 28,388$ & $\$ 387,597$ & $\$ 2$, & $67 \%$ \\
\hline Octavo & $\$ 1,079,510$ & $\$ 265,472$ & $\$ 383,905$ & $\$ 535,443$ & & $\$ \quad 487,335$ & & $12.58 \%$ \\
\hline Noveno & $\$ 1,262,865$ & $\$ 361,525$ & $\$ 540,828$ & $\$ 735,825$ & $\$ 52,356$ & $\$ \quad 672,134$ & $\$ 3,625,533$ & $16.40 \%$ \\
\hline Décimo & $\$ 1,767,283$ & $\$ 639,905$ & $\$ 880,730$ & $\$ 1,459,385$ & $\$ 85,229$ & $\$ 1,463,409$ & $\$ 6,295,940$ & $28.47 \%$ \\
\hline Total & $\$ 8,522,031$ & $\$ 2,241,998$ & $\$ 2,974,676$ & $\$ 4,259,186$ & $\$ 283,284$ & $\$ 3,829,925$ & $\$ 22,111,100$ & $100.00 \%$ \\
\hline
\end{tabular}

Fuente: Elaboración propia con base en datos de BCR (2012) y EHPM (2012).

\subsubsection{Ahorro de Hogares}

Debido a los problemas de fiabilidad que presenta la EHPM
2012 por el lado de la información de gastos, se ha realizado un ajuste, de modo que ningún hogar puede gastar más de los ingresos 
percibidos (en el caso de los deciles más bajos). En dicha situación, se evalúa la diferencia entre ingreso real y el gasto real, dando como resultado tasas negativas de ahorro para los primeros seis deciles. Por tanto, se asumirá que estos deciles gastan todo su ingreso (igualando su ingreso real con su gasto real). El gasto excedente (que se eliminó a los deciles primeros) se redistribuyó proporcionalmente entre los deciles de ingresos que presentan tasas de ahorro positivas, manteniendo la estructura de ahorro obtenida al hacer el ajuste antes de distribución de excedentes.

Por tanto, el ahorro real de los hogares, según decil, se realiza a través de la diferencia entre el ingreso y el gasto real ajustado. El dato de ahorro real total debe ser igual al "Ahorro Nacional Bruto Privado" presentado por el BCR para el año 2012, alcanzando los US\$1,913.2 millones.

Tabla 4. Distribución del ahorro por deciles de hogares para el año 2012 -Porcentaje/Dólares-

\begin{tabular}{|c|c|c|c|c|c|}
\hline Deciles & & $\begin{array}{c}\text { Ingreso Familiar } \\
\text { Real }\end{array}$ & Gasto Familiar Real & Ahorro Familiar Real & $\begin{array}{l}\text { Estructura } \\
\text { Porcentual }\end{array}$ \\
\hline Primero & $\$$ & $425,521,779.98$ & $\$ \quad 425,521,779.98$ & - & $0.0 \%$ \\
\hline Segundo & $\$$ & $751,616,414.80$ & $\$ \quad 751,616,414.80$ & - & $0.0 \%$ \\
\hline Tercero & $\$$ & $1,028,072,161.09$ & $\$ 1,028,072,161.09$ & - & $0.0 \%$ \\
\hline Cuarto & $\$$ & $1,289,029,640.90$ & $\$ 1,289,029,640.90$ & - & $0.0 \%$ \\
\hline Quinto & $\$$ & $1,589,440,836.77$ & $\$ 1,589,440,836.77$ & - & $0.0 \%$ \\
\hline Sexto & $\$$ & $1,965,423,356.40$ & $\$ 1,965,423,356.40$ & - & $0.0 \%$ \\
\hline Séptimo & $\$$ & $2,378,364,933.20$ & $\$ 2,359,990,584.33$ & $18,374,348.87$ & $1.0 \%$ \\
\hline Octavo & $\$$ & $2,966,523,271.83$ & $\$ \quad 2,780,532,961.99$ & $\$ \quad 185,990,309.85$ & $9.7 \%$ \\
\hline Noveno & $\$$ & $3,927,024,067.46$ & $\$ 3,625,532,708.11$ & $\$ \quad 301,491,359.34$ & $15.8 \%$ \\
\hline Décimo & $\psi$ & $7,703,283,537.57$ & $\$ 6,295,939,555.62$ & $\$ 1,407,343,981.94$ & $73.6 \%$ \\
\hline Total & $\psi$ & $24,024,300,000.00$ & $\$ 22,111,100,000.00$ & $\$ 1,913,200,000.00$ & $100.0 \%$ \\
\hline
\end{tabular}

Fuente: Elaboración propia con base en datos de BCR (2012) y EHPM (2012).

En la Tabla 4 se muestra que en los seis deciles de hogares con menores ingresos no existe ahorro real, mientras que los cuatro deciles más altos poseen capacidad de ahorro, en especial el décimo decil que posee la mayor tasa de ahorro, con un porcentaje de participación del $73.60 \%$ en el ahorro real total.

\subsection{Distribución de la carga tributaria por deciles de Hogares}

En el presente apartado se estima el monto real de impuestos aportados por las familias pertenecientes a cada decil. Para ello se analizarán las partidas de "Ingresos 
Tributarios" reportadas por el Ministerio de Hacienda a través del Informe de la Gestión Financiera del Estado en el ejercicio fiscal 2012.

Para esto, se han determinado estructuras porcentuales a partir de la información sobre el pago de impuestos que la EHPM de 2012 recopila, aplicándole los datos reales de recaudación publicados en el Informe de Gestión Financiera del Estado del año mencionado.
Claramente, la estructura fiscal de El Salvador (Tabla 5), evidencia que la mayor cantidad de ingresos tributarios se basan en la recaudación del Impuesto al Valor Agregado (IVA), seguido por el Impuesto Sobre la Renta (ISR). Mostrando así, que los ingresos del Estado de El Salvador se basan principalmente en los impuestos indirectos.

\section{Tabla 5. Distribución de los tributos totales los deciles de hogares para el año 2012 -Dólares-}

\begin{tabular}{|c|c|c|c|c|c|c|c|c|}
\hline \multirow[b]{3}{*}{ Decil } & \multicolumn{7}{|c|}{ Tipo de tributos } & \multirow[b]{3}{*}{ Total } \\
\hline & \multicolumn{3}{|c|}{ Tributos Directos } & \multicolumn{3}{|c|}{ Tributos Indirectos } & \multirow[b]{2}{*}{$\begin{array}{l}\text { Contribución } \\
\text { Especial Total }\end{array}$} & \\
\hline & $\begin{array}{c}\text { ISR de } \\
\text { Personas Natu- } \\
\text { rales Asalariadas }\end{array}$ & $\begin{array}{c}\text { ISR de } \\
\text { Personas } \\
\text { Naturales no } \\
\text { Asalariadas }\end{array}$ & $\begin{array}{l}\text { ISR de Personas } \\
\text { Jurídicas }\end{array}$ & $\begin{array}{l}\text { IVA Real } \\
\text { Recaudado }\end{array}$ & $\begin{array}{l}\text { Arancel Real } \\
\text { Recaudado }\end{array}$ & $\begin{array}{l}\text { Tributos a } \\
\text { Productos } \\
\text { Específicos }\end{array}$ & & \\
\hline 1 & - & $4,474.57$ & $20,064.55$ & $39,579,770.04$ & $829,357.05$ & $\$ \quad 5,806,291.83$ & $\$ \quad 1,539,224.33$ & $\$ \quad 47,779,182.36$ \\
\hline 2 & - & $7,896.13$ & $35,407.25$ & $68,737,201.03$ & $\$ \quad 1,816,008.15$ & $\$ \quad 6,832,864.97$ & $\$ \quad 2,643,242.90$ & $\$ \quad 80,072,620.42$ \\
\hline 3 & - & $23,820.96$ & $9,710.56$ & $90,255,336.25$ & $\$ \quad 3,325,817.95$ & $\$ 9,579,180.69$ & $\$ \quad 3,368,894.89$ & $\$ 106,562,761.29$ \\
\hline 4 & - & $29,890.40$ & $12,184.76$ & $\$ \quad 112,054,071.04$ & $\$ \quad 4,481,201.57$ & $\$ 10,540,806.46$ & $\$ \quad 4,017,407.46$ & $\$ 131,135,561.69$ \\
\hline 5 & - & $36,799.93$ & $15,001.41$ & $\$ \quad 138,663,150.53$ & $\$ \quad 5,928,389.15$ & $\$ 12,661,308.32$ & $\$ \quad 4,808,209.89$ & \$ $162,112,859.22$ \\
\hline 6 & - & $45,566.42$ & $18,575.06$ & $\$ \quad 168,434,470.58$ & $\$ \quad 8,937,408.50$ & $\$ 16,467,211.27$ & $\$ \quad 6,353,382.90$ & $\$ 200,256,614.73$ \\
\hline 7 & $\$ 10,725,843.63$ & $\$ 1,861,796.50$ & $99,641.52$ & $\$ \quad 198,601,319.84$ & $\$ 14,664,348.38$ & $\$ 10,613,992.86$ & $\$ \quad 8,910,830.45$ & $\$ 245,477,773.18$ \\
\hline 8 & $\$ 122,194,994.05$ & $\$ 2,320,539.80$ & $124,193.01$ & $\$ 233,049,974.51$ & $\$ 18,097,666.64$ & $\$ 22,654,842.30$ & \$ $11,782,594.17$ & \$ $410,224,804.48$ \\
\hline 9 & $\$ 115,152,380.15$ & $\$ 3,073,079.10$ & $164,468.16$ & $\$ \quad 301,920,887.29$ & $\$ 32,689,336.62$ & $\$ 19,397,125.67$ & $\$ 18,330,568.30$ & $\$ \quad 490,727,845.29$ \\
\hline 10 & $\$ 386,827,182.17$ & $\$ 54,449,636.00$ & $\$ 554,218,884.00$ & $\$ \quad 509,603,818.88$ & $\$ 88,795,365.99$ & $\$ 28,666,775.64$ & $\$ 45,958,544.71$ & $\$ 1,668,520,207.40$ \\
\hline Total & $\$ 634,900,400.00$ & $\$ 61,853,500.00$ & $\$ 554,718,130.00$ & $\$ 1,860,900,000.00$ & $\$ 179,564,900.00$ & $\$ 143,220,400.00$ & $\$ 107,712,900.00$ & $\$ 3,542,870,230.00$ \\
\hline
\end{tabular}

Fuente: Elaboración propia con base en datos de BCR (2012), EHPM (2012) y Ministerio de Hacienda (MH)

\subsection{Distribución del gasto público social transferido a los deciles de hogares}

Es importante analizar la tendencia del gasto total asignado por decil de hogares pues, como hemos visto anteriormente, hay ciertos deciles que reciben una proporción mayor de los ingresos en determinados ramos y esto puede sesgar nuestro análisis. El análisis realizado en este apartado comprende la metodología anterior, donde a partir de la EHPM 2012 se establece una estructura aplicable a los datos sobre gasto público social oficiales. 


\subsubsection{Asignación de bienes sociales por decil}

Según Nicholson (2001), "Ios bienes sociales son todos aquellos que proporcionan beneficios no exclusivos a cualquier persona de la población, y que pueden ser suministrados a un usuario más a un costo marginal igual". Entre estos se tomarán los gastos operativos en que ha incurrido el Gobierno en concepto de bienes sociales y los cuales se establecen en el
Presupuesto General de la Nación. De estos se excluye el pago de "servicio de la deuda pública" pues no implica un beneficio directo a los hogares.

Teniendo en cuenta la definición de los bienes sociales, se distribuye el total de los bienes sociales transferidos a la población en porcentajes iguales ya que todos reciben los beneficios de estos en la misma proporción, para el año 2012 corresponde a US\$347,842,800.

Tabla 6. Distribución de bienes sociales por deciles de hogar para el año 2012 -Dólares-

\begin{tabular}{|l|c|c|}
\hline \multicolumn{1}{|c|}{ Deciles } & $\begin{array}{c}\text { Estructura } \\
\text { Porcentual }\end{array}$ & Gasto en Bienes Sociales \\
\hline Primero & $10 \%$ & $\$ 34,784,280.00$ \\
\hline Segundo & $10 \%$ & $\$ 34,784,280.00$ \\
\hline Tercero & $10 \%$ & $\$ 34,784,280.00$ \\
\hline Cuarto & $10 \%$ & $\$ 34,784,280.00$ \\
\hline Quinto & $10 \%$ & $\$ 34,784,280.00$ \\
\hline Sexto & $10 \%$ & $\$ 34,784,280.00$ \\
\hline Séptimo & $10 \%$ & $\$ 34,784,280.00$ \\
\hline Octavo & $10 \%$ & $\$ 34,784,280.00$ \\
\hline Noveno & $10 \%$ & $\$ 34,784,280.00$ \\
\hline Décimo & $10 \%$ & $\$ 34,784,280.00$ \\
\hline Total & $\mathbf{1 0 0} \%$ & $\$ 347,842,800.00$ \\
\hline
\end{tabular}

Fuente: Elaboración propia con base en datos de EHPM (2012) y Ministerio de Hacienda (MH)

Como se puede observar en la Tabla 7, la estructura de la distribución del gasto público entre los deciles de hogares beneficia más a los deciles mayores, especialmente del séptimo al décimo. Esto se debe principalmente a que al tener mayores ingresos tienen acceso a más servicios, como es el caso del Instituto Salvadoreño de Seguro Social (ISSS).

Por otro lado, también puede deberse a que los bienes transferidos a los deciles mayores implican una mayor inversión de capital, 
como la infraestructura vial, que beneficia principalmente a los deciles mayores porque son estos los que tienen acceso a un medio de transporte propio, sea vehículo o motocicleta. Además, es probable que aun recibiendo una mayor proporción del gasto público, el impacto en su ingreso no sea tan significativo como las transferencias a los deciles más bajos; se procederá a analizar esto en el siguiente apartado.

\section{Tabla 7. Distribución del gasto público total estimado por deciles de hogares para el año 2012. -Dólares-}

\begin{tabular}{|c|c|c|c|c|c|c|c|c|c|}
\hline Decil & & $\begin{array}{l}\text { Gasto en } \\
\text { Infraestructura } \\
\text { Vial }\end{array}$ & $\begin{array}{l}\text { Gasto en } \\
\text { Educación }\end{array}$ & Gasto en Salud & $\begin{array}{c}\text { Gasto en Trabajo } \\
\text { y Previsión } \\
\text { Social }\end{array}$ & $\begin{array}{c}\text { Gasto en } \\
\text { Pensiones Públicas }\end{array}$ & $\begin{array}{l}\text { Gasto en Subsi- } \\
\text { dios Totales }\end{array}$ & $\begin{array}{c}\text { Gasto en } \\
\text { Bienes Sociales }\end{array}$ & Gasto Total \\
\hline 1 & $\$$ & $1,018.07$ & $\$ \quad 48,692,458.75$ & $\$ 31,604,877.85$ & $\$ \quad 1,842,039.90$ & \$ $\quad 11,028,345.70$ & $\$ 34,235,407.12$ & $\$ \quad 34,784,280.00$ & $\$ \quad 162,438,427.39$ \\
\hline 2 & $\$$ & $809,036.67$ & $\$ 57,294,474.95$ & $\$ 37,305,168.01$ & $\$ \quad 6,376,291.95$ & \$ $\quad 58,336,514,73$ & $\$ 37,951,307.41$ & $\$ 34,784,280.00$ & $\$ 232,857,073.72$ \\
\hline 3 & $\$$ & $1,832,070.75$ & $\$ \quad 61,844,549.04$ & $\$ \quad 28,720,488.05$ & $\$ 33,865,195.05$ & \$ $\quad 66,229,184.81$ & $\$ 36,837,896.03$ & $\$ 34,784,280.00$ & $\$ 264,113,663.74$ \\
\hline 4 & $\$$ & $2,326,431.89$ & $\$ \quad 66,609,565.84$ & $\$ 30,391,628.71$ & $\$ 47,893,037.35$ & $\$ \quad 18,921,015.78$ & $\$ 37,890,250.90$ & $\$ \quad 34,784,280.00$ & $\$ \quad 238,816,210.48$ \\
\hline 5 & $\$$ & $4,153,084.98$ & \$ $72,992,094.53$ & $\$ \quad 40,428,939.08$ & $\$ 56,205,832.79$ & $\$ 18,921,015.78$ & $\$ 40,028,616.72$ & $\$ 34,784,280.00$ & $\$ \quad 267,513,863.88$ \\
\hline 6 & $\$$ & $7,527,381.88$ & \$ $76,538,875.93$ & $\$ 33,132,958.46$ & $\$ 66,455,131.71$ & $\$ 29,399,539.25$ & $\$ 38,265,690.49$ & $\$ 34,784,280.00$ & $\$ \quad 286,103,857.71$ \\
\hline 7 & $\$$ & 11.48 & $\$ 77$ & $\$ 27$, & $\$ 85,44$ & $\$ 10$ & $\$ 35$ & $\$ 34$ & $\$ 28$ \\
\hline 8 & $\$$ & $14,673,270.47$ & $\$ 86,626,445.52$ & $\$ 32,610,823.68$ & $\$ 90,590,577.55$ & $\$ 15,812,549.78$ & $\$ 36,659,395.58$ & $\$ 34,784,280.00$ & $\$ 311,757,342.59$ \\
\hline 9 & $\$$ & 194.71 & $\$ 86,04$ & $\$ 32,0$ & $\$ 103,2$ & $\$ \quad 7,1$ & $\$ 34$, & $\$ 34$, & $\$ 32$ \\
\hline 10 & $\$$ & $54,297,105.32$ & $\$ 76,746$ & $\$ 21,030,526.64$ & $\$ 129,178,951.83$ & $\$ \quad 8,241,703.99$ & $\$ 33,085,442.76$ & $\$ 34,784,280.00$ & $\$ 357,364,346.99$ \\
\hline Total & $\$$ & $121,602,906.22$ & $\$ 711,004,400.00$ & $\$ 314,325,300.00$ & $\$ 621,145,300,00$ & $\$ 244,436,330.00$ & $\$ 365,195,233.69$ & $\$ 347,842,800.00$ & $\$ 2,725,552,269.91$ \\
\hline
\end{tabular}

Fuente: Elaboración propia con base en datos de BCR (2012), EHPM (2012) y Ministerio de Hacienda (MH)

\section{Impacto de la Política fiscal 2012 en la redistribución del ingreso}

Para el análisis del impacto redistributivo que tiene la Política fiscal 2012 en el ingreso de los hogares, se realizará una estimación basada en los ingresos reales percibidos por los hogares antes de aplicada la Política fiscal, a la cual se le restarán los tributos reales pagados por los hogares según deciles y se le sumará el gasto público real percibido por los hogares según deciles.
Para mayor profundidad se analizará separadamente cada elemento de la ecuación anterior, por medio de una serie de cálculos necesarios para comprender el resultado final de la Política fiscal 2012 en su función redistributiva de los ingresos. Debe tomarse en cuenta que el tema de evasión de tributos queda fuera del alcance del presente trabajo de investigación. 


\subsection{Incidencia de la política tributaria}

Es relevante evaluar la incidencia tributaria efectiva para determinar qué deciles de hogares son los que soportan en última instancia la carga tributaria, a través del mayor aporte de tributos. Para ello, se estima la razón carga tributaria sobre ingreso para cada decil de hogares, y por cada tributo, además del tributo total. Los resultados se observan en la siguiente tabla.

Tabla 8. Carga tributaria distribuida por deciles de hogares para el año 2012 -Porcentaje-

\begin{tabular}{|c|c|c|c|c|c|c|c|c|}
\hline \multirow[b]{3}{*}{ Deciles } & \multicolumn{7}{|c|}{ Tipo de tributos } & \multirow[b]{3}{*}{ Total } \\
\hline & \multicolumn{3}{|c|}{ Tributos Directos } & \multicolumn{3}{|c|}{ Tributos Indirectos } & \multirow[b]{2}{*}{$\begin{array}{l}\text { Contribución } \\
\text { Especial Total }\end{array}$} & \\
\hline & $\begin{array}{c}\text { ISR de } \\
\text { Personas } \\
\text { Naturales } \\
\text { Asalariadas }\end{array}$ & $\begin{array}{c}\text { ISR de } \\
\text { Personas } \\
\text { Naturales } \\
\text { No } \\
\text { Asalariadas }\end{array}$ & $\begin{array}{c}\text { ISR de } \\
\text { Personas } \\
\text { Jurídicas }\end{array}$ & $\begin{array}{l}\text { IVA Real } \\
\text { Recaudado }\end{array}$ & $\begin{array}{c}\text { Arancel } \\
\text { Real } \\
\text { Recaudado }\end{array}$ & $\begin{array}{l}\text { Tributos a } \\
\text { Productos } \\
\text { Específicos }\end{array}$ & & \\
\hline Primero & $0.00 \%$ & $0.00 \%$ & $0.00 \%$ & $9.30 \%$ & $0.19 \%$ & $1.36 \%$ & $0.36 \%$ & $11.2 \%$ \\
\hline Segundo & $0.00 \%$ & $0.00 \%$ & $0.00 \%$ & $9.15 \%$ & $0.24 \%$ & $0.91 \%$ & $0.35 \%$ & $10.7 \%$ \\
\hline Tercero & $0.00 \%$ & $0.00 \%$ & $0.00 \%$ & $8.78 \%$ & $0.32 \%$ & $0.93 \%$ & $0.33 \%$ & $10.4 \%$ \\
\hline Cuarto & $0.00 \%$ & $0.00 \%$ & $0.00 \%$ & $8.69 \%$ & $0.35 \%$ & $0.82 \%$ & $0.31 \%$ & $10.2 \%$ \\
\hline Quinto & $0.00 \%$ & $0.00 \%$ & $0.00 \%$ & $8.72 \%$ & $0.37 \%$ & $0.80 \%$ & $0.30 \%$ & $10.2 \%$ \\
\hline Sexto & $0.00 \%$ & $0.00 \%$ & $0.00 \%$ & $8.57 \%$ & $0.45 \%$ & $0.84 \%$ & $0.32 \%$ & $10.2 \%$ \\
\hline Séptimo & $0.45 \%$ & $0.08 \%$ & $0.00 \%$ & $8.35 \%$ & $0.62 \%$ & $0.45 \%$ & $0.37 \%$ & $10.3 \%$ \\
\hline Octavo & $4.12 \%$ & $0.08 \%$ & $0.00 \%$ & $7.86 \%$ & $0.61 \%$ & $0.76 \%$ & $0.40 \%$ & $13.8 \%$ \\
\hline Noveno & $2.93 \%$ & $0.08 \%$ & $0.00 \%$ & $7.69 \%$ & $0.83 \%$ & $0.49 \%$ & $0.47 \%$ & $12.5 \%$ \\
\hline Décimo & $5.02 \%$ & $0.71 \%$ & $7.19 \%$ & $6.62 \%$ & $1.15 \%$ & $0.37 \%$ & $0.60 \%$ & $21.7 \%$ \\
\hline
\end{tabular}

Fuente: Elaboración propia con base en datos de BCR (2012), EHPM (2012) y Ministerio de Hacienda (MH)

Se observa que tanto en el ISR de personas asalariadas, personas no asalariadas, personas jurídicas, arancel y contribución especial; es el décimo decil el que soporta la mayor carga tributaria, contrario a lo que sucede con el IVA y el tributo a productos específicos donde es el primer decil quien soporta la mayor parte de la carga tributaria. Lo anterior conduce al total de tributos donde el décimo decil es el que aporta el mayor porcentaje de tributos totales, con el $21.7 \%$; la mayor carga tributaria para el décimo decil deriva de los tributos directos. 


\subsubsection{Impacto Redistributivo de la} Política Tributaria

En el presente apartado se identificará la naturaleza de cada uno de los tributos, y del total de tributos, determinando si existe condición de progresividad o regresividad. Para ello se utilizan las herramientas para el análisis de tributos, descritas en el
Capítulo I; de este modo se obtiene el Îndice de Concentración e Índice Kakwani para tributos. Asimismo se determinará si existe o no, un incremento en la desigualdad de ingresos al aplicar los tributos, para lo cual se estimará el Índice de Gini para cada nueva estructura de ingreso obtenida de la resta de los diferentes tributos, y el tributo total.

\section{Tabla 9. Evolución de los tributos para el año 2012}

\begin{tabular}{|c|c|c|c|c|}
\hline \multirow{3}{*}{ Tributo } & \multicolumn{4}{|c|}{ Indicador } \\
\hline & \multicolumn{2}{|c|}{ Redistribución } & \multicolumn{2}{|c|}{ Progresividad } \\
\hline & Gini Inicial & $\begin{array}{c}\text { Gini después de } \\
\text { Tributos }\end{array}$ & Cuasi Gini & $\begin{array}{l}\text { Índice Kakwani } \\
\text { (K) }\end{array}$ \\
\hline ISR Personas Naturales Asalariadas & \multirow{8}{*}{0.4207} & 0.411 & 0.779 & 0.358 \\
\hline ISR Personas Naturales No Asalariadas & & 0.419 & 0.854 & 0.433 \\
\hline ISR Personas Jurídicas & & 0.409 & 0.899 & 0.478 \\
\hline IVA & & 0.425 & 0.369 & -0.052 \\
\hline Arancel & & 0.419 & 0.621 & 0.200 \\
\hline Tributos a Productos Específicos & & 0.422 & 0.269 & -0.151 \\
\hline Contribución Especial & & 0.420 & 0.527 & 0.107 \\
\hline Tributos Totales & & 0.399 & 0.546 & 0.125 \\
\hline
\end{tabular}

Fuente: Elaboración propia con base en datos de la Tabla 41, utilizando el software DAD Versión 4.6.

A partir de los indicadores de progresividad (ver Tabla 9), se puede analizar que de acuerdo al índice de concentración cuasiGini, se encuentra que el ISR de personas jurídicas, es el tributo que más representa la característica de progresividad, es decir, está diseñado de modo que no se afecte a los hogares con menores ingresos, favoreciendo así a los más pobres. Lo contrario sucede con el IVA y el tributo a productos específicos, que efectivamente afecta de manera negativa el ingreso de los hogares más necesitados.

Asimismo, el Índice Kakwani señala directamente la progresividad o regresividad de los tributos. En el caso de los tributos progresivos, se tiene el ISR de Personas Naturales Asalariadas, Naturales no Asalariadas, Personas Jurídicas, el Arancel, y las Contribuciones Especiales, siendo el tercero el que muestra una mayor progresividad con un valor de 0.478 . Por tanto, 
los tributos regresivos son el IVA y el que se aplica a Productos Específicos $(-0.052$ y -0.151 , respectivamente). En cuanto a los tributos totales, se observa que poseen la características de "progresividad", aunque poco marcada; tal como muestra el Índice cuasi- Gini. Asimismo, se obtiene un estimado del índice de Kakwani positivo (0.125) representando un nivel no tan alto de progresividad.

La implementación de las políticas tributarias de 2012 mejoró la distribución de los ingresos entre deciles de hogares, especialmente la implementación del ISR de Personas Jurídicas (0.409), que se observa con la disminución del Índice de Gini después de tributos respecto al valor de Gini del ingreso pre-política tributaria. De igual forma, se observa y confirma la regresividad del IVA y el tributo a productos específicos.

\subsection{Análisis de la Política de Gasto Público Social}

Por su importancia como herramienta redistribuidora del ingreso, se evaluará la política de gasto público social, analizando el impacto generado sobre la distribución del ingreso entre deciles de hogares, y profundizando la condición de progresividad o regresividad del gasto público, así como su efecto en la desigualdad del ingreso.

\subsubsection{Impacto Redistributivo de la Política de Gasto Público Social}

Según el Informe de Gestión Financiera del Estado del Ministerio de Hacienda, la política de gastos estaba enfocada en priorizar la cobertura de los programas básicos en materia de educación, salud, protección social, entre otros, a través de diferentes programas y proyectos de apoyo. Por tanto, es necesario analizar el impacto que ha tenido la política del gasto público social sobre la redistribución del ingreso real, para establecer si el diseño y la manera de implementar estas políticas han logrado los objetivos trazados. Para esto se presentan a continuación los indicadores relevantes que sirven como herramienta para determinar el impacto que ha tenido el gasto público. 
Tabla 10. Evaluación del gasto público social para el año 2012

\begin{tabular}{|c|c|c|c|c|}
\hline \multirow{3}{*}{ Gasto Ejecutado } & \multicolumn{4}{|c|}{ Indicadores } \\
\hline & \multicolumn{2}{|c|}{ Redistribución } & \multicolumn{2}{|c|}{ Progresividad } \\
\hline & $\begin{array}{c}\text { Gini Antes } \\
\text { de GPS* }\end{array}$ & Gini después de GPS & Cuasi Gini & Índice Kakwani \\
\hline Infraestructura Vial & \multirow{7}{*}{0.4207} & 0.4216 & 0.612 & -0.1908 \\
\hline Educación & & 0.4111 & 0.092 & 0.3285 \\
\hline Salud & & 0.4147 & 0.088 & 0.3330 \\
\hline Trabajo y Previsión Social & & 0.4191 & 0.359 & 0.0615 \\
\hline Transferencias Públicas & & 0.4142 & 0.031 & 0.3895 \\
\hline Bienes Sociales & & 0.4147 & 0.000 & 0.4207 \\
\hline GPS Total & & 0.3882 & 0.104 & 0.3171 \\
\hline
\end{tabular}

Fuente: Elaboración propia con base en datos de EHPM (2012), BCR (2012) y MH (2012), utilizando el software DAD Versión 4.6. *GPS: Gasto público social.

En general, la introducción de las Políticas fiscales ejercen una redistribución en el ingreso real inicial —pasando de un coeficiente de Gini de 0.42 a 0.38 - , siendo el gasto público social en educación el que en mayor medida mejora la distribución principal del ingreso real (0.411). Caso contrario es el de Infraestructura vial, generando una redistribución desigual y superior a la inicial (0.421). Esto implica que en cierta medida, las políticas de gasto social disminuyen la desigualdad generada a partir del ingreso real.

En este punto, se vuelve interesante el grado de progresividad o regresividad que muestra el Índice Kakwani. A pesar del rubro de infraestructura vial el cual está enfocado en los deciles superiores, el gasto público social es progresivo; siendo el más progresivo el rubro en bienes sociales (0.42), seguido por el rubro de transferencias públicas (0.38), salud pública (0.33) y educación (0.32).

La política de gastos efectuada en el período 2012, provoca una redistribución del ingreso real, mejorando la desigualdad que se muestra antes del implemento de los programas y proyectos sociales. De igual forma, la mayoría de rubros de dicho gasto son progresivos — siendo los gastos en transferencias públicas, salud pública y educación los que han tenido mayor impacto-, dándole mayor equidad a la nueva distribución de ingreso, de igual forma, dicha política no puede considerarse como una política "pro-pobre", más bien se mantiene relativamente equilibrada entre los estratos sociales distribuidos por deciles de hogar. 


\subsection{Análisis del Efecto Redistributivo de la Política fiscal 2012}

Antes de evaluar el efecto redistributivo de la Política fiscal total, se hará un análisis del impacto redistributivo que tiene la política social y los bienes sociales en el ingreso real, ambos de manera separada. Una vez se realice el análisis anterior, se evaluará el impacto redistributivo final, con la aplicación total de la Política fiscal 2012.

La política social se obtiene al aplicar tributos y el gasto público social (sin bienes sociales) al ingreso real. Con la implementación de la política social se logra mejorar de manera considerable la distribución de ingresos, y por lo tanto, se logra reducir de manera significativa la desigualdad de ingresos existente entre deciles. El decil primero aumenta su participación en los ingresos con un $2.21 \%$, lo que representa un incremento del $18.77 \%$ de sus ingresos; en cambio, el décimo decil ve reducida su participación en el ingreso total, pasando de un $32.06 \%$ a un $27.81 \%$, representando el $17.47 \%$ de sus ingresos.

Se observa que a pesar de la mejora percibida en la distribución del ingreso, el crecimiento del ingreso real para todos los deciles es negativo, pues el gasto en bienes sociales no es suficiente para compensar el total de tributos aportados por los hogares.
El resultado es una disminución del $13.30 \%$ de los ingresos reales totales, resultando más afectado el decil décimo con una decrecimiento de sus ingresos en $21.21 \%$. Es necesario tener en cuenta que para que una medida de Política fiscal tenga un efecto positivo real y significativo, debe no solo mejorar la estructura porcentual de distribución del ingreso (mejora relativa) que acerca al objetivo de equidad, sino también es importante que los ingresos reales de las familias incrementen en términos absolutos. La política social, a diferencia del gasto en bienes sociales, sí satisface la mejora relativa y absoluta.

Una vez analizado el impacto redistributivo del gasto público social y bienes sociales, se evaluará el impacto redistributivo de la Política fiscal global, obteniendo el ingreso real total que perciben los hogares. En la Tabla 11 se aprecia una mejora sustancial en la distribución de ingresos para los deciles más bajos; la nueva estructura porcentual muestra un aumento en los primeros siete deciles de hogares, experimentando un incremento de sus ingresos (después de la Política fiscal) del $83.51 \%$, siendo el primer decil el que mayor mejora mostró con un crecimiento del $26.95 \%$ del ingreso. Lo contrario sucede con los deciles con mayores ingresos que se ven afectados por la implementación de la Política fiscal, disminuyendo el ingreso percibido por los tres deciles más altos en un $24.64 \%$. 


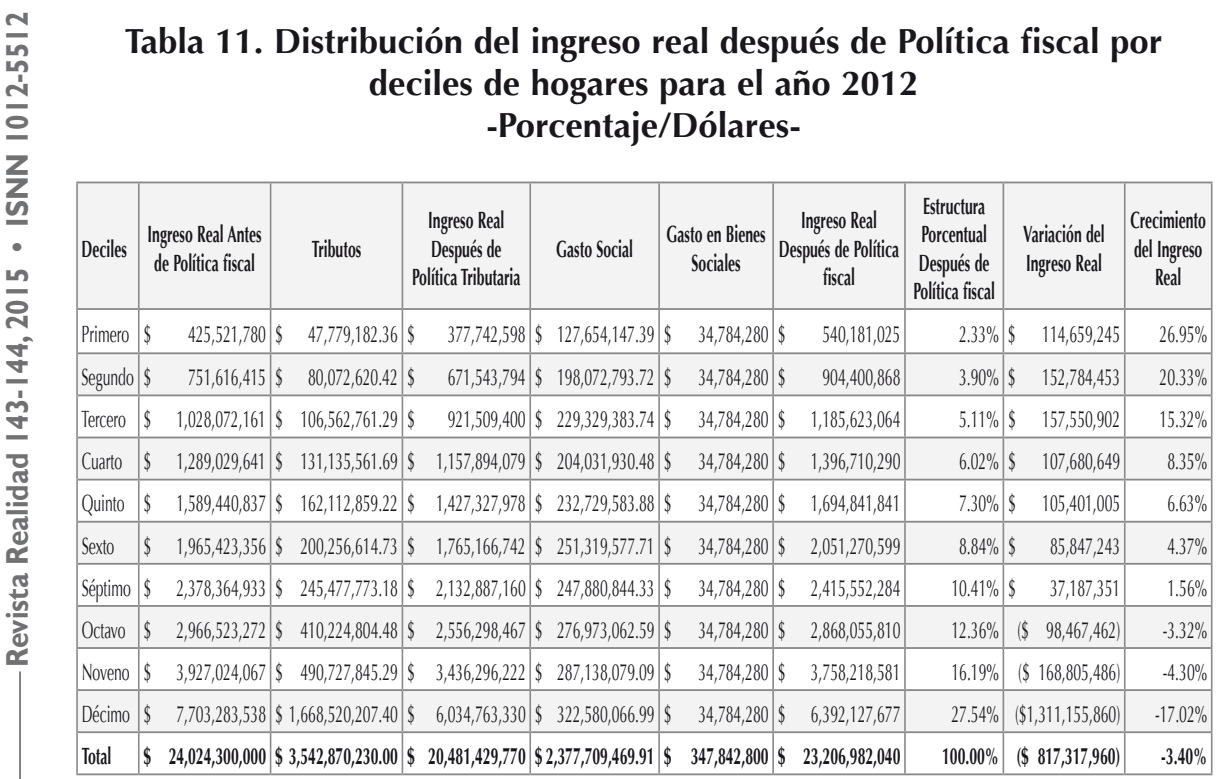

Fuente: Elaboración propia con base en datos de EHPM (2012), BCR (2012) y MH (2012)

La siguiente tabla resume, por medio de indicadores, los resultados obtenidos para profundizar el análisis de los distintos escenarios, en especial el efecto que ha tenido la Política fiscal en la redistribución del ingreso.

\section{Tabla 12. Evaluación del ingreso real en sus distintos escenarios}

\begin{tabular}{|l|c|c|c|c|c|c|}
\hline \multicolumn{2}{|c|}{$\begin{array}{c}\text { Concentración } \\
\text { Estimado }\end{array}$} & Estimado & Inicial & $\begin{array}{c}\text { Después de } \\
\text { Política Social }\end{array}$ & $\begin{array}{c}\text { Después de } \\
\text { Bienes Sociales }\end{array}$ & $\begin{array}{c}\text { Después } \\
\text { de Política } \\
\text { fiscal }\end{array}$ \\
\cline { 5 - 8 } & 0.4207 & & & & 0.19 & 0.1837 \\
\hline Gini Inicial & 0.3695 & Índice DER & 0.1922 & 0.1851 & 0.3922 & 0.3639 \\
\hline $\begin{array}{l}\text { Gini después de Política } \\
\text { Social }\end{array}$ & 0.3922 & Enajenación & 0.4204 & 0.3695 & 0.5214 & 0.5421 \\
\hline $\begin{array}{l}\text { Gini después de Bienes } \\
\text { Sociales }\end{array}$ & 0.3639 & Identificación & 0.4989 & 0.5381 & 0.514 \\
\hline $\begin{array}{l}\text { Gini después de Política } \\
\text { fiscal (Final) }\end{array}$ & & & & & & \\
\hline
\end{tabular}

Fuente: Elaboración propia con base en datos de EHPM (2012), BCR (2012) y MH (2012) utilizando el software DAD Versión 4.6. 
El valor del Índice de Gini es menor después de implementada la Política fiscal (0.364), por lo que se evidencia una mejora en la distribución de los ingresos, reduciéndose la desigualdad existente entre deciles de hogares.

En cuanto al índice de polarización Duclos, Esteban y Ray (DER), se experimenta una disminución - poco significativa - de la polarización de los ingresos, pasando de 0.192 a 0.184 , es decir, se ha reducido la brecha entre grupos de hogares. El decrecimiento del índice DER se debe a dos elementos de polarización: el primero es la disminución del grado de enajenación o heterogeneidad entre distintos deciles de hogares (0.42 antes de Política fiscal y 0.364 después de Política fiscal), por lo que se da una reducción en la brecha de desigualdad existente entre deciles de hogares, lo que conlleva una reducción en el antagonismo entre grupos. De igual forma, el DER se ve contrarrestado, aunque en menor medida, por el aumento del grado de homogeneidad entre la población de un mismo decil, el cual pasa a ser de 0.498 a 0.542 , por lo que se da una mayor identificación de los hogares dentro de un mismo decil, ya sea por atributos socioeconómicos comunes como podrían ser los beneficios percibidos del sector público que mejora sus ingresos.

La mayor desigualdad en la distribución de ingresos antes de la Política fiscal, respecto al ingreso después de la Política fiscal, es posible observarla con la Curva de Lorenz para cada momento, la cual se observa a continuación.

La línea verde representa la diagonal de equidad perfecta o línea de equidistribución. Se evidencia la menor desigualdad en los ingresos después de implementada la Política fiscal, dado que la curva antes de la Política fiscal se contrae y se acerca más a la línea de equidistribución.

La implementación de la Política fiscal 2012 ha generado un impacto positivo sobre la redistribución del ingreso, y aunque la mejora es poca, en términos relativos, se observa que el objetivo redistributivo se ha alcanzado, logrando los resultados esperados: una distribución del ingreso más equitativa, o lo que es lo mismo, menos desigual. 


\section{Gráfico 3. Curva de Lorenz para ingresos reales antes y después de Política fiscal El Salvador 2012}

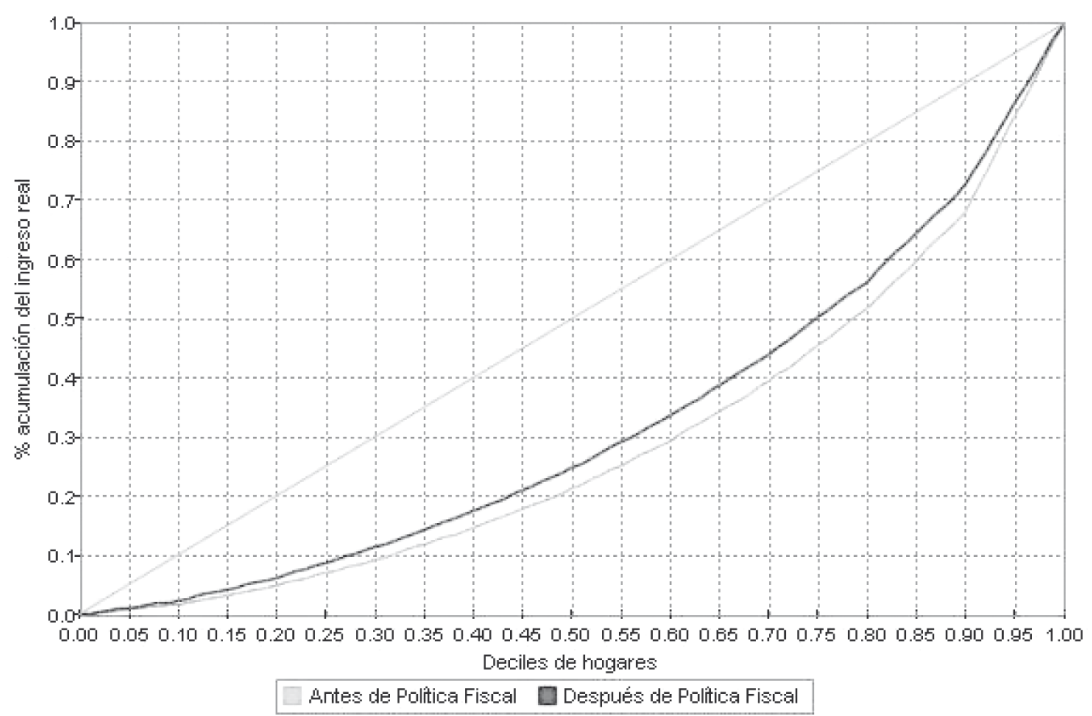

Fuente: Elaboración propia con base en datos de EHPM (2012), BCR (2012) y MH (2012)

\section{Conclusiones y recomendaciones}

Las reformas fiscales implementadas en el quinquenio 20092014, han reducido —en cierta medida- la regresividad que ha caracterizado al sistema impositivo salvadoreño. Sin embargo, estas no han modificado el esquema tributario tradicional, caracterizado por ser poco equitativo y basado en impuestos al consumo. Cabe destacar que la política tributaria para el año 2012, en general, ha presentado una tendencia hacia la progresividad y la mayoría de los tributos han generado una mejora en la distribución del ingreso de los hogares. A pesar de esto, el hecho de que ciertos tributos a productos específicos y el IVA sean regresivos, generan un problema grave sobre el ingreso de los hogares salvadoreños, ya que en promedio, estos impuestos aportan el 56\% de los ingresos tributarios del Estado; carga que está siendo soportada por los deciles más pobres.

La existencia de tributos regresivos no implica, necesariamente, una desmejora del bienestar social; el beneficio general (y sobre todo de los deciles con menores ingresos) se dará en la medida en que exista gasto público social de carácter progresivo, o dirigido a satisfacer las necesidades 
sociales de los que poseen menores recursos. Es decir, una buena gestión del gasto contrarresta cualquier política tributaria regresiva, generando un resultado positivo.

De manera general, en el año 2012 se implementó una política tributaria con tendencia progresiva, donde se buscaba que los que poseen los mayores recursos se convirtieran en los mayores contribuyentes. Sobre los tributos de carácter regresivo, son varios factores los que influyen en el aporte de los más pobres, no solo el tributo en sí mismo, pues existe cierto factor de preferencias y patrones de consumo que llevan a estas familias a consumir más, en términos relativos, de lo que consumiría una familia con más recursos. La política de gastos efectuada en el período 2012 provoca una redistribución del ingreso real, mejorando la desigualdad que se muestra antes del implemento de los programas y proyectos sociales.

A pesar del incremento de la recaudación tributaria a lo largo del periodo 2000-2012, este no ha sido suficiente para financiar las erogaciones del sector público. Por tanto, es necesario crear un esquema de política tributaria que no dependa en gran porcentaje del endeudamiento interno o externo, el cual ha alcanzado casi el 50\% como porcentaje del PIB, que lo vuelve insostenible en el mediano y largo plazo. Esto se traduce en la necesidad inminente de crear las condiciones adecuadas para la implementación de una Reforma fiscal profunda y sostenible.

En cuanto a los gastos, hay que hacer un mayor esfuerzo en las áreas que impactan positivamente a los deciles más bajos, como es salud y educación. De igual forma se tienen los subsidios, que si bien benefician a las familias más pobres, es necesaria la focalización de estos, tomando en cuenta que muchas familias de bajos ingresos no tienen acceso a ciertos recursos subsidiados (como el agua o la electricidad), buscando al mismo tiempo generar ahorro en las finanzas del Estado.

Es necesario hacer un mayor esfuerzo por aumentar la recaudación fiscal pues, si bien es cierto, se ha avanzado significativamente, aún no lo suficiente para contrarrestar las insuficiencias de la política tributaria. Ante esto, se recomienda ampliar la base tributaria mediante la incorporación del sector informal, esto generaría un incremento de la recaudación de renta y por ende podría incrementar el Producto Interno Bruto. El aumento de la recaudación fiscal puede ser abonado de diferentes fuentes, entre ellas el combate hacia la evasión fiscal que juega un papel importante, ya que la insuficiencia de los ingresos tributarios en el país tiene como principal causa el alto nivel de incumplimiento tributario 
de los contribuyentes. Por ello se recomienda fortalecer los procesos de fiscalización y jurídicos, además de la tipificación de incumplimientos y aplicación de sanciones.
De igual forma se debe hacer un esfuerzo por evitar las deficiencias en la operación de la Unidad Penal de Hacienda para la investigación del delito.

\section{Referencias}

- Álvarez, J., Arias, J. \& Moreno, O. (2010). Incidencia de la Política fiscal en la redistribución del ingreso en El Salvador en el año 2008 (Tesis de pregrado). Universidad Centroamericana "José Simeón Cañas". Antiguo Cuscatlán.

- Barreix, A., Roca, J. \& Villela, L. (s.f.). Política fiscal y Equidad. Recuperado de http://www.comunidadandina.org/public/libro_ EquidadFiscal_bid.pdf

- Capo, O. (2002). Efecto redistributivo, estabilizador y aseguramiento de la Política fiscal. Universidad de Zaragoza.

- Cubero, R. \& Vladkova, I. (2011). "Equidad y Política fiscal: Los efectos de la distribución de los impuestos y el gasto social en Centroamérica". Revista Internacional de Presupuesto Público n 75.

- Díaz, R. \& Merlos, M. (2000). El impacto redistributivo de la Política fiscal en El Salvador en 1998 (Tesis de pregrado). Universidad Centroamericana "José Simeón Cañas". Antiguo Cuscatlán.

- DiGestyC. (2012). Encuesta de Hogares de Propósitos Múltiples. Ciudad Delgado: DIGESTYC.

- DIGeSTYC. (2013). Encuesta de Hogares de Propósitos Múltiples 2012. Recuperado de http://www.digestyc.gob.sv/EHPM2012/digestyc/ resultado.pdf

- GOES. (2013). El camino del cambio en El Salvador. Legados de cuatro años de gestión. San Salvador: s. e.

- Gradín, C. \& del Río, C. (2001). La medición de la desigualdad. Recuperado de http://decon.edu.uy/ mito/nip/desigualdad.pdf

- Ibarra Mares, A. (2010). Introducción a las Finanzas Públicas. Colombia: Facultad de Economía-UNAM

- Lasso de La Vega, M. C. \& Urrutia, A. M. (s.f.) Desigualdad y Polarización de la Distribución de Renta a Nivel Mundial. Recuperado de http://www.alde.es/encuentros/anteriores/vieea/autores/L/137.doc

- Lazo, F. (1996). Reconversión de la Política Fiscal en El Salvador. El Salvador: Fundaungo, $1^{\circ}$ edición. 
- Mancero, X. (s.f.). Revisión de algunos indicadores para medir desigualdad. Recuperado de http://www.eclac.cl/deype/mecovi/docs/ TALLER6/21.pdf

- Martín, E. \& Olmedo, L. (1999). Progresividad y efecto redistributivo de las transferencias públicas en Andalucía. Recuperado de http://www. revistaestudiosregionales.com/documentos/articulos/pdf611.pdf

- Medina, A., Castaneda, R., Maldonado, E. \& Pérez Trejo, C. (2013). Política fiscal salvadoreña, 2007-2012. ICEFI. Recuperado de http://icefi. org/publicaciones/politica-fiscal-salvadorena-2007-2013.

- Medina, F. (2001). Consideraciones sobre el Índice de Gini para medir la concentración del ingreso. Recuperado de http://repositorio.cepal.org/ bitstream/handle/11362/4788/S01020119_es.pdf?sequence=1

- Ministerio de Hacienda. (2012a). Informe de la gestión financiera del Estado. San Salvador.

- Ministerio de Hacienda. (2012b). Disposiciones Administrativas de Carácter General. San Salvador. Recuperado de http://www. mh.gob.sv/portal/page/portal/PMH/Temas/Operaciones_Aduaneras/ Marco_Legal?_piref476_3495122_476_3480898_3480898. tabstring=Directivas_Generales:2012

- Ministerio de Hacienda. (2012c). Impuestos a pagar. San Salvador. Recuperado de http:/www.mh.gob.sv/portal/page/portal/PMH/Temas/ Operaciones_Aduaneras/Proceso_Despacho/Proceso_Aduanero/ Impuestos\%20a\%20pagar

- Nicholson, W. (2001). Microeconomía Intermedia. Bogotá: McGraw-Will.

- Pleitéz, W. (2001). La Política fiscal en El Salvador en el período 19782001: Desafíos y perspectivas de la dolarización. San Salvador: PNUD.

- Santiere, J. (2002). Impacto de los impuestos sobre distribución del ingreso en la Argentina en 1997. Argentina: Banco Mundial.

- Secretaría de Hacienda y Crédito Público de México, SHCP. (2010). Recuperado de http://www.shcp.gob.mx/egresos/pef/ppef/ppef_06/temas/ expo_motivos/em02.pdf

- Urquidi, V. (1973). La Política fiscal en el desarrollo económico de la América Latina, Ensayos de Política fiscal. México: Fondo de Cultura Económica. 